\title{
A review on the Application of Empirical Models to Hydrate Formation Prediction
}

\author{
Aijaz Abbasi ${ }^{1}$ and Fakhruldin Mohd Hashim \\ Mechanical Engineering Department, Universiti Teknologi PETRONAS, Bandar Seri Iskandar, 31750 \\ Tronoh, Perak, Malaysia.
}

\begin{abstract}
In deepwater hydrocarbon transportation pipeline, the production may decrease and operational cost and time are increasing due to the growth rate of hydrate. The pressure of deepwater pipeline is comparatively high, so it is entirely possible to form the hydrate formation conditions and pose a major operational and safety challenge. This work provides a review on empirical models for hydrate formation prediction in deepwater gas pipeline. The correlation and empirical models are presented with the hydrate formation temperature described as a function of pressure and gas gravity. This study could possibly provide a milestone for predicting PVT and heat transfer effects on hydrate formation in deepwater pipeline.
\end{abstract}

Keywords. Hydrate formation pressure, Empirical correlations, Gravity methods and Hydrate prediction.

\section{Introduction}

The hydrocarbon mixture (e.g. gas, water and oil) flowing through pipeline at the underwater / subsea level, mixture of flowing fluid cools down either rapidly or gradually depending on the effects of quantified thermodynamic conditions that may slow down the path of flow [1]. The rate of natural gas hydrates formation is bring about by multiple conditions of pressure, volume and temperature [2], [3] and [4]. This research is reviewing and proposing improved empirical models and correlations to forecast the hydrate formation circumstances in deepwater pipeline. The hydrate formation takes place when there is interaction between light hydrocarbons and water under conditions of thermodynamics and heat mass transfer. The accumulation of flowing particles of hydrates which are carried by the fluid are being deposited on the wall of the pipeline $[3,5]$. Most light molecules such as methane, ethane, propane, isobutene, normal butane, nitrogen, carbon dioxide, and hydrogen sulfide will form hydrates under specific conditions of pressure and temperature[4]. However, several heavy hydrocarbons shown in Figure 1, such as benzene, cyclopentane, cyclohexane, methylcyclopentane, methylcyclohexane, isopentane and 2,3-dimethylbutane have been recently identified as hydrate formers[6].

Furthermore, gas hydrates are crystalline form i.e. methane and water [6,7], at high pressure and low temperature regime when methane concentration exceeds solubility limit. One volume of natural

\footnotetext{
${ }^{1}$ Corresponding author : aijazz.abbasi@gmail.com
}

This is an Open Access article distributed under the terms of the Creative Commons Attribution License 2.0, which permits unrestricted use, distribution, and reproduction in any medium, provided the original work is properly cited. 
gas hydrate discharges 164 volumes of methane and 0.8 volume of fresh water at standard temperature and pressure.

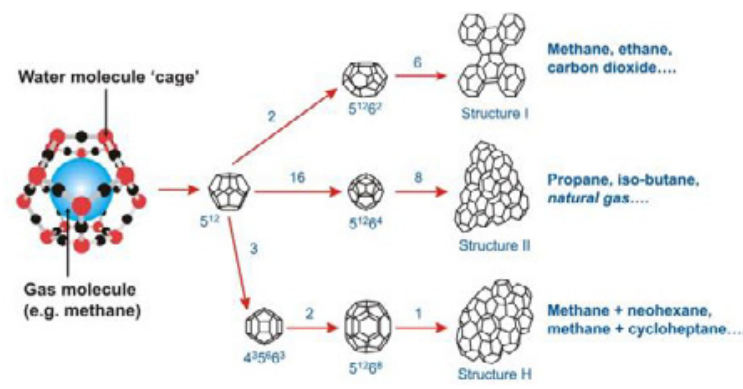

Figure 1. Cavities for hydrates of Structure-I, Structure-II, and Structure-H [6].

\section{Hydrate Formation Correlations and Empirical Models}

Numerous mathematical models or correlations and Empirical models have been presented in the literature to predicting the hydrate formation conditions.

\section{$2.1 \mathrm{~K}$-value method}

The vapor solid equilibrium constant are predicting hydrate formation conditions under the basis of hydrates solid solutions. This method is restricted to the hydrate formation pressure up to 4,000psia, 2000psia, 1000psia for methane, ethane, and propane; for isobutane and hydrogen sulfide; and for carbon dioxide respectively [8].

$$
K_{v s, i}=\frac{y_{i}}{x_{i}}
$$

Where:

$\mathrm{y}_{\mathrm{i}}=$ molecule friction of ith hydrocarbon component of gas phase under consideration of free water $\mathrm{x}_{\mathrm{i}}=$ molecule fraction of hydrocarbon component of solid phase under free water basis.

$$
\sum_{i=1}^{n} \frac{y_{i}}{k_{v s, i}}=1
$$

\subsection{Gas-gravity plot method (Katz's)}

The pressure and temperature that hydrate forms in gas gravity with the apparent molecular weight and air of a natural gas flowing mixture [8]. This method is a simple graphical technique that is useful for an initial estimate of hydrate formation conditions in pipeline. The hydrate formation diagram was made from a partial amount of experimental data.

\subsection{Empirical correlation}

It is also called (Holder and Makogon) method, is specially selected for pure gases correlations those depends on the range of temperature for each gas $[8,9]$.

$$
P=\exp \left(a+\frac{b}{T}\right)
$$

Where, $a$ and $b=$ empirical correlations e.g. temperature range for each gas.

$$
\ln \mathrm{p}=2.3026 \beta+0.1144\left(\mathrm{~T}+\mathrm{KT}^{2}\right)
$$

Where, $\beta=2.681-3.811 \gamma+1.679 \gamma 2$,

$$
\mathrm{K}=-0.006+0.011 \gamma+0.011 \gamma 2
$$




\subsection{The charts of permissible expansion}

These charts and curves are more helpful for rough design of values, chokes, joints etc. These curves are limited to methane, with an average error of $10 \%[8,9]$.

\subsection{Thermodynamic}

It is bases on the statistical thermodynamic approach that is interacting among water and natural gas molecules those forming the crystal lattic. [8]: -

Table 1. Types of gases and materials [6]

\begin{tabular}{|c|c|}
\hline Type & Component \\
\hline Hydrocarbon hydrate formers & $\mathrm{C}_{1} \mathrm{C}_{2} \mathrm{C}_{3} \mathrm{i}-\mathrm{C}_{4} \mathrm{n}-\mathrm{C}_{4}$ \\
\hline Non-hydrocarbon hydrates formers & $\mathrm{CO}_{2} \mathrm{~N} \mathrm{H}_{2} \mathrm{~S}$ \\
\hline Hydrocarbon non-hydrate formers & i- $\mathrm{C}_{5} \mathrm{n}-\mathrm{C}_{5} \mathrm{C}_{6}$ \\
\hline Inhibitors & $\mathrm{MeOH} \mathrm{EG} \mathrm{EtOH} \mathrm{NaCl} \mathrm{CaCl} \mathrm{CaH}_{2}$ \\
\hline
\end{tabular}

\subsection{ANN Model}

Artificial neural network are predicting the conditions for pure gases, mixture of gases and inhibitors. ANN is predicting accurate phase equilibria and PVT properties [9]. Inputs for ANN are the temperature and composition e.g. hydrocarbons, non-hydrocarbons and inhibitors as shown in Table 1. Phase equilibrium data will be examine by dividing into single, binary, ternary and multi component system are shown in Table 1. The four ANN model are considered as input variables[9].

\subsubsection{Model-A}

The relationship is based on the assumption that, pressure ' $\mathrm{P}$ ' depends on temperature ' $\mathrm{T}$ ' and specific gravity ' $\gamma$ '

$$
\mathrm{P}=\mathrm{f}_{1}(\mathrm{~T}, \gamma)
$$

Where, $\gamma=$ molecular weight for pure gases or apparent molecular weight (AMW) of pure gas mixture

\subsubsection{Model-B}

The correlation is conveyed in terms of configuration of pure hydrocarbon components and their mixtures

$$
\mathrm{P}=\mathrm{f}_{2}\left(\mathrm{~T}, \gamma_{\mathrm{c}_{1}}, \gamma_{\mathrm{c}_{2}}, \gamma_{\mathrm{c}_{3}}, \gamma_{\mathrm{i}-\mathrm{c}_{4}}, \gamma_{\mathrm{n}-\mathrm{c}_{4}}\right)
$$

Where $y=$ molecule $\%$ of each component

\subsubsection{Model-C}

The non-hydrocarbon hydrates former are carbon dioxide and nitrogen

Where, $\gamma=$ molecule $\%$ of each component

$$
P=f_{3}\left(T, \gamma_{c_{1}}, \gamma_{c_{2}}, \gamma_{c_{3}}, \gamma_{i-c_{4}}, \gamma_{n-c_{4}}, \gamma_{\mathrm{co}_{2}}, \gamma_{N}, \gamma_{\mathrm{H}_{2} S}\right)
$$




\subsubsection{Model-D}

The hydrocarbon non-hydrate formers are i-pentane, n-pentane and hexane plus and inhibitors including methanol, sodium chloride, ethylene glycol, calcium chloride and ethanol.

$$
\mathrm{P}=\mathrm{f}_{3}\left(\mathrm{~T}, \gamma_{\mathrm{c}_{1}}, \gamma_{\mathrm{c}_{2}}, \gamma_{\mathrm{c}_{3}}, \gamma_{\mathrm{i}-\mathrm{c}_{4}}, \gamma_{\mathrm{n}-\mathrm{c}_{4}}, \gamma_{\mathrm{co}_{2}}, \gamma_{\mathrm{N}}, \gamma_{\mathrm{H}_{2} \mathrm{~S}}, \gamma_{\mathrm{c}_{5}}, \gamma_{\mathrm{c}_{6}}, \gamma_{\mathrm{MeOH}}, \gamma_{\mathrm{EG}}, \gamma_{\mathrm{EtOH}}, \gamma_{\mathrm{NaCL}}, \gamma_{\mathrm{CaCl}_{2}}\right)
$$

\subsection{Berger Method}

This method is used to calculate pressure and specific gravity of gas with the help of temperature and explicit equations [8].

\subsection{Motiee Method}

This method is used to determine the six coefficients which can correlate temperature, pressure and specific gravity[10].

\subsection{Sloan Method}

This method is used to determine the fifteen correlations those would correlate temperature range 34 to $60 \mathrm{~F}^{\mathrm{o}}$, pressure range 65 to $1500 \mathrm{psi}$ and specific gravity range 0.552 to 0.9 [8].

\section{Developing an improved correlations and Empirical model}

The hydrate formation knowledge is vital, when making a gas condensing element. A computer base program is used, to calculate the natural gas hydrate formation conditions by above discussed correlations and empirical models. The computer base program requires the data to calculate hydrate formation conditions as input. Program either predicts temperature as input pressure or vice versa. The requirement of program is according to the specific gravity of gas, temperature or pressure is as input. And the experimental data to compare the computer base generated data in output as results. Also the error analysis is used to check the accuracy and performance of gas hydrate formation correlation and experimental data.

In absence of inhibitors and at the same temperature, a gas with lighter specific gravity forms hydrate at higher pressure, but considering the pressure of components such as propane, isobutene and nitrogen. The presence of propane and isobutene in a gas mixture decreases the hydrate formation pressure and increases hydrate formation temperature, while the pressure of nitrogen in a gas mixture increases and decreases the hydrate formation temperature. The composition of natural gas plays an important role in determining the hydrate formation temperature and pressure. Sodium chloride has a higher inhibition effects than methanol at the same concentration, it is very obvious at higher pressure. And the inhibition effects of ethylene glycol are inferior to that of methanol at the same concentration.

Methane hydrates are clathrate structures those trap methane molecules in a solid ice crystal form. Mostly the flowing gases are combine with water molecules, they form hydrates in deepwater pipeline. The K-value method is the first model for predicting hydrate formation conditions, which utilize the vapor solid equilibrium constants for hydrate formation prediction. Artificial neural network is bases on computation for non-linear functions. Most existing experimental data has been compiled and compared with ANN models. The best methods for determining circumstances of hydrate formation are to experimentally measure the formation at the different temperature, pressure and flowing fluid composition of natural gas mixtures. Therefore, accurate and simplified model for predicting the conditions of natural gas hydrate are described. In most of the places the SAS (statistical analysis software) is used in regression model to find the best empirical models and correlation among the variables such as specific gravity, water vapor pressure, temperature of gas mixture, vapor pressure. The correlations are comparing with the empirical correlations and an 
obtained result, as to indicate in more accurate in prediction of hydrate formation pressure or temperature conditions. The basic reasons of developing improved correlations are;

- The improve correlations estimate the hydrate formation temperature or pressure for a variety of gas hydrate formation in the presence of absence of inhibitors.

- These correlations are easy to use and they are applicable even with a simple calculator.

- Improved correlations are unique since none of the available correlations in the literature can predict the hydrate formation conditions for complex system including inhibitors; in addition the new correlations proved to be much more accurate than the common correlations.

- The correlations are useful for a wide range of temperature (to 90oF) and pressure (to $12000 \mathrm{psi}$ )

\section{Conclusions}

This study has presented a review on the empirical models and correlations for the hydrate formation prediction, in which it is, described relationship along pressure, temperature and gas gravity. Most of the correlations were based on experimental data, hence limited to specific scenario only. If the same model is to be used for other sites then needs to be modifications accord for measurement error and data cross correlations. The empirical correlation can be used for predicting of hydrate free zone judging from its prediction of hydrate formation, which will be demonstrating the reliability of simulation tool for gas mixture flowing in deepwater pipeline.

\section{References}

[1] M. Mork and J. S. Gudmundsson, "Rate of hydrate formation in subsea pipeline," 12th International oil field chemistry symposium, Norwegian University of Science and Technology 7491 Trondheim, (2001)

[2] J. Hilbert, "Flow Assurance: Wax deposition and gelling in subsea oil pipeline," SPE Asia Pasific Oil and Gas conference and exhibition Queensland, Australia, (2010)

[3] A. Abbasi and F. Mohd Hashim, Applied Mechanics and Materials, 607-611. (2014)

[4] N. Edwards, R. Mir, E. Willoughby, K. Schwalenberg, and C. Scholl, "The assessment and evaluation of offshore gas hydrate deposits using seafloor controlled source electromagnetic methodology," IEEE, (2010)

[5] S. Mokhatab, R. J. Wilkens, and K. J. Leontaritis, Taylor and Francis Group, LLC, vol. Energy Source Part-A, 29:39-45, 7, (2007)

[6] S. Ameripour, "Prediction of gas hydrate formation conditions in production and surface facilities," Master of Science, Petroleum Engineering, Texas A\&M University, (2005)

[7] K. Sain and H. Gupta, International association for Gondwana Research, GR-00781, p. 13, $21(2012)$

[8] E. D. Sloan, American Mineralogist, vol. 89, p. 7, (2004)

[9] A. A. Elgiblay and A. M. Elkamel, "A new correlation for predicting hydrate formation conditions for various gas mixtures and inhibitors," Fluid Phase Equilibrium, 153, 10-22. (1998)

[10] G. Zahedi, Z. Karami, and H. Yaghoobi, Energy Conversion and Management, 50, p. 8, 06. (2009) 